\title{
Combined Adsorption of the Copper and Chromium Cations by Clinoptilolite of the Sokyrnytsya Deposit
}

\author{
Vira Sabadash ${ }^{1 *}$, Jaroslaw Gumnitsky' ${ }^{1}$ Oksana Lyuta ${ }^{1}$ \\ 1 Lviv National Polytechnic University, Lviv, Ukraine \\ * Corresponding author's e-mail: virasabadash@gmail.com
}

\begin{abstract}
In the paper, the assessment of the impact of heavy metals on water objects, namely copper and chromium was performed, and the methods for their neutralization were defined. A scientifically grounded method for the selection of natural zeolite for the purification of wastewater from heavy metals has been developed, provided that they are jointly present. The physicochemical characteristics of two metals related to heavy metals are presented: copper and chromium. The methods for determining the sorption capacity of natural zeolite for copper and chromium compounds, as well as the methods of analytical control of the wastewater components were presented. The results of the experimental studies on the combined adsorption of copper and chromium cations by natural zeolite under static conditions were presented. The changes in the chemical composition of the zeolite surface as a result of heavy metal sorption have been investigated. The influence of the nature of the ions and the $\mathrm{pH}$ of the adsorption medium on the selectivity of the heavy metal ions extraction by zeolite was analyzed. A diagram of the composition of the solution, depending on the $\mathrm{pH}$ values, was constructed. The $\mathrm{pH}$ of the beginning of deposition of the corresponding heavy metal hydroxides on the zeolite surface was calculated. While analyzing the results of experimental studies on the combined adsorption of copper and chromium ions, it was found that the copper ions are significantly better adsorbed by the sorbent than the chromium ions. Despite the same concentration of the chromium and copper ions in solution, $\mathrm{Cu}^{2+}$ is extracted selectively. As can be seen from the results of experimental studies, the concentration of copper on the surface of the sorbent increases from $0.628 \%$ mass at a concentration of $0.01 \mathrm{~g} / \mathrm{dm}^{3}$ to $47.380 \%$ mass at a concentration of $1 \mathrm{~g} / \mathrm{dm}^{3}$. The studies on the static activity of clinoptilolite for the copper and chromium ions indicate a simultaneous mechanism of the process, which involves ion exchange and physical adsorption. The concentration of the chromium ions on the surface of the sorbent after adsorption depends on the increase of the concentration of $\mathrm{Cr}^{3+}$ in the original solution to a lesser extent. The results of the studies on the combined adsorption of the $\mathrm{Cu}^{2+}$ and $\mathrm{Cr}^{3+}$ ions indicate the possibility of their chromatographic separation, which makes their further use possible.
\end{abstract}

Keywords: copper, chromium, heavy metals, adsorption, zeolite.

\section{INTRODUCTION}

Heavy metals (mercury, lead, cadmium, zinc, copper, chromium, arsenic) belong to widely spread and highly toxic contaminants. They are commonly used in various industrial enterprises; therefore, despite the treatment measures, the content of heavy metal compounds in industrial wastewater is quite high (Han et al. 2009). Large amounts of these compounds enter the oceans (El Wahab et al. 2015). In the areas contaminated by industrial waters, their concentration in solutions and suspensions increases extremely (Sabadash et al. 2017, Ates et al. 2016). These are emissions from the industrial and domestic effluents, from the smoke and dust of industrial plants, especially galvanic ones, with the exhaust gases of internal combustion engines. Since all heavy metals are highly toxic and MPC averages about $0,1 \mathrm{mg} / \mathrm{l}$, it is advisable to use the sorption methods to clean up such effluents, which allow trace amounts of contamination to be extracted (Wang et al. 2007, Kithome et al. 1999).

In the previous studies, the adsorption properties of the zeolite of the Transcarpathian field 
were studied, it is based on clinoptilolite, with respect to $\mathrm{Cu}$ (II) and $\mathrm{Cr}$ (VI) ions (Sabadash et al. 2018, Lee et al. 2016). It has been found that the adsorption isotherm is s-shaped and belongs to the II type of isotherm. After the formation of the monomolecular adsorption layer, the adsorption is continued. This leads to the appearance of a dimolecular layer. The combined adsorption of copper (II) and chromium (VI) ions in an anionic form on natural zeolite was investigated and its adsorption capacity during their coadsorption was determined. A significant difference in their sorption capacity was found, which is much higher for the copper cations than for the anionic form of chromium (Wang et al. 2019, Liu et al. 2019).

In the wastewaters of the galvanic industries, the chromium cation $\mathrm{Cr}^{3+}$ from the chrome plating process is often found, so it is advisable to investigate the combined adsorption of copper and chromium cations (Salih et al. 2019).

The purpose of the study was to investigate the change in the elemental composition of the zeolite surface as a result of sorption of a mixture of heavy metal cations from wastewater.

\section{MATERIALS AND METHODS}

For the purpose of this study, samples of copper sulfate $\mathrm{CuSO}_{4} \cdot 5 \mathrm{H}_{2} \mathrm{O}$ weighing $3.93 \mathrm{~g}$ and chromium nitrate $\mathrm{Cr}\left(\mathrm{NO}_{3}\right)_{3}-4.58 \mathrm{~g}$ were introduced into a 1L flask. The salts were dissolved in distilled water. The contents were thoroughly mixed until completely dissolved. The solution was brought to a volume of 1 liter. In the prepared solution, the ratio of mass amounts of copper and chromium ions was 1: 1 .

From the prepared solution, 6 samples were taken with a volume of $2 \mathrm{ml}, 10 \mathrm{ml}, 20 \mathrm{ml}, 40 \mathrm{ml}$, $80 \mathrm{ml}$ and $120 \mathrm{ml}, 160 \mathrm{ml}, 200 \mathrm{ml}$, and added to $200 \mathrm{ml}$ volumetric flasks. The content of each sample was brought to the mark with distilled water and a sample of natural zeolite in the weight of $2 \mathrm{~g}$ was added to the container.

The content of each sample was mixed and closed with a lid; then it was kept for three days in a thermostat at $20 \pm 0.5^{\circ} \mathrm{C}$. After three days, the solution was filtered off and the zeolite was dried to the constant weight. With the help of $\mathrm{X}$-ray fluorescence analyzer, the amount of the adsorbed copper and chromium ions was determined (Dignos et al. 2019).
Energy-dispersive X-ray fluorescence analyzer "EXPERT 3L" is designed to determine the mass fraction of elements with an atomic number from 12 (magnesium) to 92 (uranium) in homogeneous monolithic samples. For the destination, the analyzer is a universal direct-indicating device which, without changing calibration and reconfiguration, determines the mass fraction (\%) of chemical elements in the samples of unknown composition and arbitrary shape. Moreover, according to the results from the determination of the quantitative composition of the sample, the analyzer automatically determines the concentration according to the existing government standards. The method of energy-dispersive X-ray fluorescence analysis (XRF) of substances was implemented in the analyzer. The advantage of this method over others is the complete preservation of the object of analysis from damage. The method allows to determine the composition of the substance layer of the object, which is analyzed with a thickness of $10 \mu \mathrm{m}$ (мкм) to $1 \mathrm{~mm}$, depending on the density and composition of the layer. The principle of the XRF action is the excitation of atoms of the control object by an external source of ionizing radiation and subsequent registration of the characteristic X-ray emission of the atoms. The energy of the characteristic Xray emission is uniquely related to the structure of the atomic level of a particular chemical element (Esmaeili et al. 2019).

For a qualitative analysis, it is sufficient to use the X-ray spectrometer to determine the energy of the characteristic X-ray emission lines from the object and to identify the elements by their value. Quantitative analysis is based on the statement of proportionality between the intensity of the element's characteristic X-ray emission and its content in the control object.

\section{RESULTS AND DISCUSSION}

As a result of the analysis of the adsorbed zeolite on the X-ray fluorescence analyzer, the data regarding on the amount of adsorbed heavy metal ions were obtained (Table 1). The elemental composition of the zeolite surface is shown in Figure 1.

Depending on the concentration of heavy metal ions in solution, their concentration on the surface of the sorbent changes (Hyvlud et al. 2019, Mahmoodi et al. 2019). While analyzing 
Table 1. Dependence of the amount of adsorbed heavy metal cations by zeolite on their concentration in the initial solution

\begin{tabular}{|c|c|c|}
\hline \multirow{2}{*}{$\begin{array}{c}\text { The } \\
\text { concentration of } \\
\text { ions in the initial } \\
\text { solution, } \mathrm{kg} / \mathrm{dm}^{3}\end{array}$} & \multicolumn{2}{|c|}{$\begin{array}{c}\text { The amount of adsorbed } \\
\text { heavy metal ions, } \%\end{array}$} \\
\cline { 2 - 3 } & Copper (Cu) & Chromium (Cr) \\
\hline 0.01 & $0.628 \pm 0.019$ & $0.459 \pm 0.016$ \\
\hline 0.05 & $29.026 \pm 0.159$ & $2.966 \pm 0.061$ \\
\hline 0.1 & $28.631 \pm 0.158$ & $2.740 \pm 0.046$ \\
\hline 0.2 & $35.591 \pm 0.383$ & $2.047 \pm 0.051$ \\
\hline 0.4 & $43.728 \pm 0.360$ & $2.123 \pm 0.048$ \\
\hline 0.6 & $37.096 \pm 0.286$ & $2.377 \pm 0.052$ \\
\hline 0.8 & $41.604 \pm 0.181$ & $1.840 \pm 0.040$ \\
\hline 1 & $47.380 \pm 0.255$ & $1.679 \pm 0.036$ \\
\hline
\end{tabular}

the results of the experimental studies, the authors found out that the copper ions are much better adsorbed by the sorbent than the chromium ions. Despite the same concentration of chromium and copper ions in the solution, a selective extraction of $\mathrm{Cu}^{2+}$ occurs.

As can be seen from the results of experimental studies, the concentration of copper on the surface of the sorbent increases from $0.628 \%$ mass at a concentration of $0.01 \mathrm{~g} / \mathrm{dm}^{3}$ to $47.380 \%$ mass at a concentration of $1 \mathrm{~g} / \mathrm{dm}^{3}$. The concentration of the chromium ions on the surface of the sorbent after adsorption depends on the increase in the concentration of $\mathrm{Cr}^{3+}$ in the initial solution to a lesser extent.

The adsorption of ions on the surface of the sorbent in contact with the solution is caused by the electrostatic interaction forces, but it is not necessarily selective. There are several factors that affect the ability of a sorbent to adsorb this or that type of ions (Zasidko et al. 2019). The following is an analysis of these factors.

The size of the ion. If all the other factors are the same, then basically an ion that is about the size of the lattice ion which it replaces, will be adsorbed.

Ion charge effect. If the other factors are the same, the multi-charged ion will be more easily adsorbed than the single-charged, since the adsorption force depends in part on the electrostatic interaction between the ion and the opposite charged centers on the sorbent surface.

Concentration effect. If all the factors are the same, the ion with higher concentration will be adsorbed first. In addition, the adsorption capacity of any ion is directly proportional to its concentration in the solution. In the experiment, the radii of the metals are close in size and are in one period. The atomic radius of the copper is slightly larger than the chromium $\mathrm{R} \mathrm{Cr}=1.27 \AA$, $\mathrm{R} \mathrm{Cu}=1.28 \AA$. According to Goldsmith and Pauling, $\mathrm{R} \mathrm{Cr}=0.35 \ldots 0,52 \AA, \mathrm{R} \mathrm{Cu}=0.98 \AA$. According to Belov and Bokij, $\mathrm{R} \mathrm{Cr}(3+)=0.64 \AA$, $\mathrm{R} \mathrm{Cu}(2+)=0.8 \AA$ (Salih et al. 2019). Therefore, despite the fact that the charge of chromium ion is higher, it is obvious that the radius of the atom is crucial in the sorption process. This confirms the better sorption of copper than chromium.

According to the Panet - Faience - Khan law, if two or more ions are contained in a solution

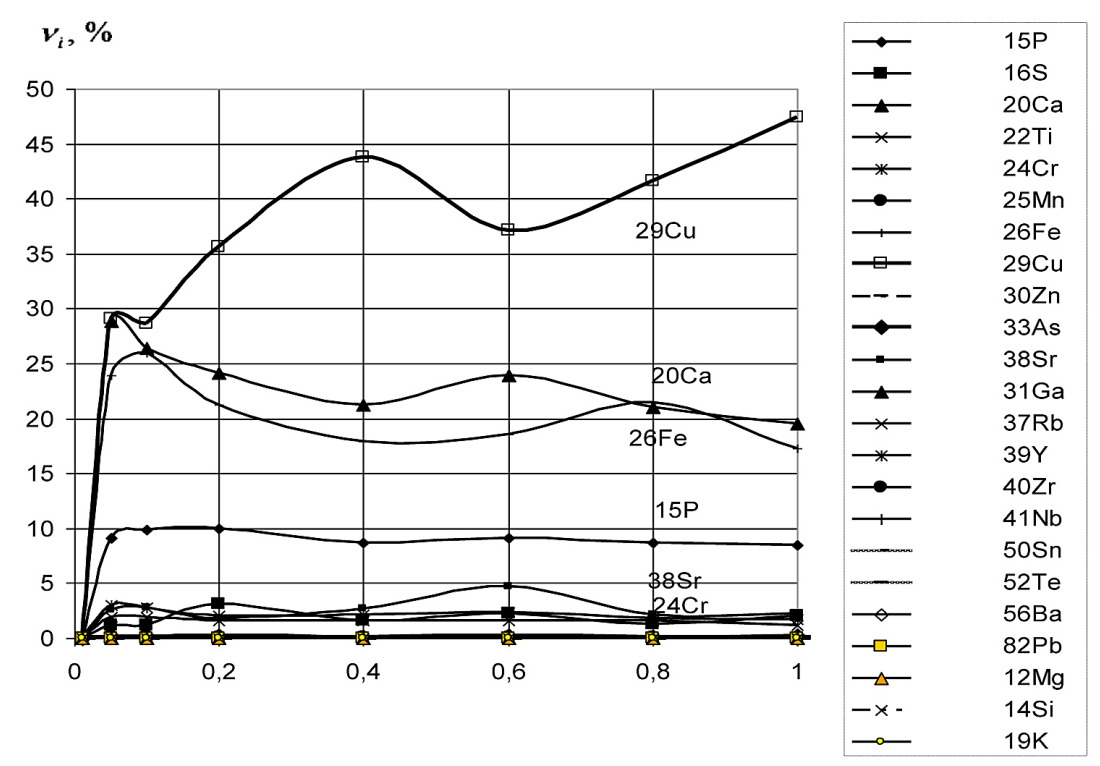

Fig. 1. Mass fraction of elements on the zeolite surface depending on the initial concentration of $\mathrm{Cr}^{3+}$ and $\mathrm{Cu}^{2+}$ ions in solution 
and the other factors are the same, the ion which, forms the compound with the least solubility with one of the ions of the crystalline lattice of the sorbent, will be adsorbed first.

In our case, the solution contains the same concentrations of the copper and chromium ions. Since these compounds are formed by strong acids and weak bases, hydrolysis takes place in the solution. The acid and insoluble hydroxides of the corresponding metals are formed according to the equation of reactions

$$
\begin{gathered}
\mathrm{CuSO}_{4}+2 \mathrm{H}_{2} \mathrm{O} \rightarrow \mathrm{Cu}(\mathrm{OH})_{2} \downarrow+\mathrm{H}_{2} \mathrm{SO}_{4} \\
\mathrm{Cr}\left(\mathrm{NO}_{3}\right)_{3}+3 \mathrm{H}_{2} \mathrm{O} \rightarrow \mathrm{Cr}(\mathrm{OH})_{3} \downarrow+3 \mathrm{HNO}_{3}
\end{gathered}
$$

According to the reference data, copper hydroxide has a much lower solubility than chromium hydroxide. The solubility products of the formed compounds are presented in table 2 .

To display the phase composition of a twocomponent solution of heavy metals, a diagram was created in MEDUSA (Make Equilibrium Diagram Using Sophisticated Algorithms) and HYDRA (Hydrochemical Equilibrium Constant Database) programs.

While analyzing the diagram, it can be seen that soluble complexes are contained in the solution in the $\mathrm{pH}$ range $0-3$. At $\mathrm{pH} 3.7$, insoluble $\mathrm{Cr}_{2} \mathrm{O}_{3}$ is formed. In the $\mathrm{pH}$ range $4-6$, copper

Table 2. The solubility product of $\mathrm{Cu}(\mathrm{OH})_{2}$ and $\mathrm{Cr}(\mathrm{OH})_{3}$ depending on the acidity of the medium

\begin{tabular}{|c|c|c|}
\hline Compound & Solubility product & $-\lg (\mathrm{S})$ \\
\hline $\mathrm{Cr}(\mathrm{OH})_{3}$ & $4,0^{-10^{-15}}$ & 14.4 \\
\hline $\mathrm{Cu}(\mathrm{OH})_{2}$ & $1 \cdot 10^{-19}$ & 19.0 \\
\hline
\end{tabular}

hydroxosulfates are formed, which are insoluble compounds.

If the solubility of $\mathrm{Cu}(\mathrm{OH})_{2}$, which is formed by hydrolysis (1), is equal to $1 \cdot 10^{-19}$ (Sabadash et al. 2017), the concentration of $\mathrm{Cu}^{2+}$ in the solution at the beginning of the experiment is $0.016 \mathrm{~mol} / \mathrm{dm}^{3}$, then, based on this, the $\mathrm{pH}$ of the beginning of deposition of copper will be equal to

$$
\begin{gathered}
{\left[\mathrm{Cu}^{2+} \mathrm{OH}^{-}\right]^{2}=S P_{\mathrm{Cu}(\mathrm{OH})_{2}}=1 \cdot 10^{-19}} \\
p H=14-p O H=14-\left(-\lg \sqrt{\frac{S P}{\left[\mathrm{Cu}^{2+}\right.}}\right)= \\
=14-\left(-\lg \sqrt{\frac{1 \cdot 10^{-19}}{0.016}}\right)=5,39
\end{gathered}
$$

where: $S P-$ solubility product.

If the solubility of $\mathrm{Cr}(\mathrm{OH})_{3}$ which is formed by hydrolysis (2) is $4.0 \cdot 10^{-15}$ (Wang et al. 2019), the concentration of $\mathrm{Cr}^{3+}$ in the initial solution at the beginning of the experiment is $0.019 \mathrm{~mol} / \mathrm{dm}^{3}$, then, based on this, $\mathrm{pH}$ of the beginning of deposition of chromium will be equal

$$
\begin{aligned}
& {\left[\mathrm{Cr}^{3+} \rrbracket\left[\mathrm{OH}^{-}\right]^{3}=S P_{\mathrm{CrOH}_{3}}=4 \cdot 10^{-15}\right.}
\end{aligned}
$$

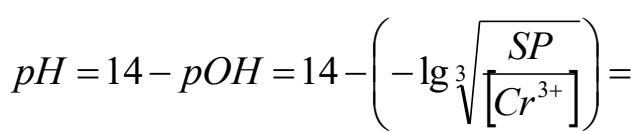

$$
\begin{aligned}
& =14-\left(-\lg \sqrt[3]{\frac{4 \cdot 10^{-15}}{0.019}}\right)=9,77
\end{aligned}
$$

According to the calculated data, it is seen that at fixed $\mathrm{pH}$ values, the copper will be more rapidly precipitated than chromium and, according to the Panet-Faience-Khan law, it will be better adsorbed, which was established experimentally.

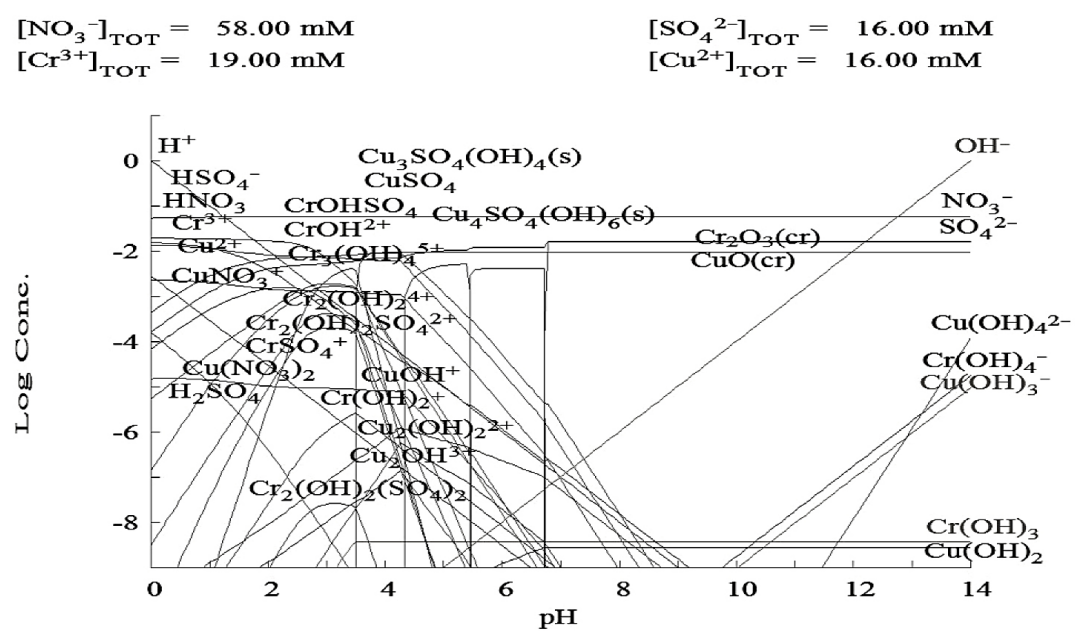

Fig. 2. Logarithmic diagram of the composition of a two-component system depending on $\mathrm{pH}$ 
Obviously, this is the reason for selective removal of copper from the two-component system. In addition, this is confirmed by the previous studies (Zasidko et al. 2019, Bolisetty et al. 2019).

During the experimental studies, a decrease in the content of calcium, magnesium, iron and rare earth metals on the surface of the sorbent was detected. This is explained by the ion-exchange interaction of hydrogen ions and heavy metals from the studied solutions with zeolite. As a result, these exchanged cations move from the surface of the sorbent to the solution.

\section{CONCLUSIONS}

The conditions of precipitation of the hydroxides of the corresponding metals were calculated and a logarithmic diagram of the composition of the two-component system depending on the $\mathrm{pH}$ was constructed. In the research, the following goals were achieved:

- The elemental composition of the surface of the sorbent by X-ray fluorescence method after the adsorption of heavy metals from a twocomponent system containing $\mathrm{Cu}^{2+}$ and $\mathrm{Cr}^{3+}$ ions was investigated.

- The mechanism of sorption extraction of copper and chromium from solution was theoretically substantiated.

- It was established that the selectivity of metal extraction is influenced by the radius of the element and the solubility of its hydroxides.

\section{REFERENCES}

1. Han, R., Zhang, J., Han, P., Wang, Y., Zhao, Z., Tang, M., 2009. Study of equilibrium, kinetic and thermodynamic parameters about methylene blue adsorption onto natural zeolite Chemical Engineering Journal, 145(3), 496-504.

2. El Wahab, M.R.A., Seliem, M.K., Mohamed, E.A. E. R., Shahien, M.G., 2015. International Journal of Bioassays, 4(10), 4423-4430.

3. Sabadash, V., Mylanyk, O., Matsuska, O., Gumnitsky, J., 2017. Kinetic regularities of copper ions adsorption by natural zeolite. Chemistry Chemical Technology, 4 (11), 459-462.

4. Ates, A., Akgül, G., 2016. Modification of natural zeolite with $\mathrm{NaOH}$ for removal of manganese in drinking water. Powder technology, 287, 285-291.

5. Wang, S., Ariyanto, E., 2007.Competitive adsorption ofmalachite green and $\mathrm{Pb}$ ions on natural zeolite. Journal of Colloid and Interface Science, 314(1), 25-31.
6. Kithome, M., Paul, J. W., Lavkulich, L. M., Bomke, A.A., 1999. Effect of $\mathrm{pH}$ on ammonium adsorption by natural zeolite clinoptilolite. Communications in soil science and plant analysis, 30(9-10), 1417-1430.

7. Sabadash, V., Gumnitsky, J., Lyuta, O., Pochapska, I., 2018. Thermodynamics of (NH4+) cation adsorption under static conditions. Chemistry \& Chemical Technology, 12(2), 143-146.

8. Lee, K.Y., Park, M., Kim, J., Oh, M., Lee, E.H. 2016. Equilibrium, kinetic and thermodynamic study of cesium adsorption onto nanocrystalline mordenite from high-salt solution. Chemosphere, 150, 765-77.

9. Wang, Z., Tan, K., Cai, J., Hou, S., Wang, Y., Jiang, P., Liang, M. , 2019. Silica oxide encapsulated natural zeolite for high efficiency removal of low concentration heavy metals in water. Colloids and Surfaces A: Physicochemical and Engineering Aspects, 561, 388-394.

10. Liu, X., Tian, R., Ding, W., He, Y., Li, H., 2019. Adsorption selectivity of heavy metals by Na-clinoptilolite in aqueous solutions. Adsorption, 25(4), 747-755.

11. Salih, A.M., Williams, C., Khanaqa, P.A., 2019. Heavy metal removals from industrial wastewater using modified zeolite: study the effect of pre-treatment. Journal of the University of Garmian, 6, 2.

12. Dignos, E.C.G., Gabejan, K.E.A., Olegario-Sanchez, E.M., Mendoza, H.D., 2019. The comparison of the alkali-treated and acid-treated naturally mined Philippine zeolite for adsorption of heavy metals in highly polluted waters. In IOP Conference Series: Materials Science and Engineering (Vol. 478, No. 1, p. 012030). IOP Publishing.

13. Esmaeili, A., Mobini, M., Eslami, H., 2019.Removal of heavy metals from acid mine drainage by native natural clay minerals, batch and continuous studies. Applied Water Science, 9(4), 97.

14. Hyvlud, A., Sabadash, V., Gumnitsky, J., Ripak, N., 2019. Statics and Kinetics of Albumin Adsorption by Natural Zeolite. Chemistry Chemical Technology, 13(1), 95-100.

15. Mahmoodi, N.M., Saffar-Dastgerdi, M.H., 2019. Zeolite nanoparticle as a superior adsorbent with high capacity: Synthesis, surface modification and pollutant adsorption ability from wastewater. Microchemical Journal, 145, 74-83.

16. Zasidko, I., Polutrenko, M., Mandryk, O., Stakhmych, Y., Petroshchuk, N., 2019. Complex Technology of Sewage Purification from Heavy-Metal Ions by Natural Adsorbents and Utilization of Sewage Sludge. Journal of Ecological Engineering, 20(5)., 209-216.

17. Bolisetty, S., Peydayesh, M., Mezzenga, R., 2019. Sustainable technologies for water purification from heavy metals: review and analysis. Chemical Society Reviews, 48(2), 463-487. 